\title{
Crown and Cusp Dimensions of the Maxillary First Molar: A Study of Sexual Dimorphism in Indian Jat Sikhs
}

\author{
Gaurav Agnihotri ${ }^{1}$ and Vimal Sikri \\ ${ }^{1}$ Department of Anatomy, Government Medical College, Amritsar, Punjab, India, and ${ }^{2}$ Government Dental College, \\ Amritsar, Punjab, India
}

ABSTRACT The human first maxillary molar provides clues about evolution and is functionally important. Crowns of maxillary molars have four main cusps, each having an independent growth pattern and different evolutionary background. The study aims to quantify the morphometric criterion for the maxillary first molar giving a special emphasis to sexual dimorphism. Measurements of the first maxillary molar were taken on 100 casts of Jat Sikh students (50 males, 50 females) studying in the local medical college in the age group of 17-21 years. The Jat

Teeth exhibit the least cellular turnover of the body's structure, and they are readily accessible for examination. Tooth size standards based on odontometric investigations can be used in age and sex determination (Black, 1902). The variations in tooth size are influenced by genetic and environmental factors. Whenever it is possible to predict the sex, identification is simplified because then only missing persons of one sex need to be considered. In this sense identification of sex takes precedence over age (Camps, 1976). Various features like tooth morphology and crown size are characteristic for males and females (Dayal et al., 1998).

Among Sikhs, sub-castes have been grouped into several categories like Jats, Aroras, Khatris, Ramgarhias, Majhabis, Rajputs and Namdharis. Historically, Jat Sikhs are landowners, farmers, and warriors. Traditionally, the Jat Sikhs have been endogamous at caste level and exogamous at the (gotra) sub-caste level (Sidhu, 2003). These are divided into numerous clans like Aulak, Bains, Bajwa, Bal, Bath, Bhullar, Chahal, Dhaliwal, Dhillon, Dosanjh, Gill, Grewal, Hundal, Kang, Randhawa, Sahota, Sidhu and Virk. There are 31 million Jats in South Asia. The majority of the 11 million Jat Sikhs in India live in Punjab, a state in northern India. The Jat Sikhs are believed to be the merged descendants of the original Indo-Aryans and a later addition of Indo-Scythian tribes (Dhillon, 1994).

The present study establishes the morphometric characterizations of the first maxillary molar in Indian Jat Sikhs. The study has been conducted with a special emphasis on the impact of sex factor on the morphometry of the first maxillary molar.

Crowns of maxillary molars have four main cusps,
Sikh community of Punjab is endogamous at the caste level. Unpaired t-tests were used to compare the samples for males and females. There is statistically significant sexual dimorphism $(\mathrm{P}<0.01)$ for the maxillary first molar's crown and cusp components in the Jat Sikhs. The sequence of dimorphism in cusp dimensions corresponds to the order of formation of the cusps. The percentage sexual dimorphism for the hypocone is high (right $7.2 \%$, left 7.4\%). Dental Anthropology 2010;21(1):1-6.

namely the paracone, protocone, metacone and hypocone. Each cusp has an independent growth pattern (Kraus and Jordan, 1965) and a different evolutionary background (Osborn, 1907). The paracone is the first to appear both ontogenetically and phylogenetically and is regarded as the successor of the single cone of the reptilian haplodont dentition (Patterson, 1956). The hypocone tends to develop latest in terms of ontogeny and phylogeny, and it differentiates from the lingual cingulum (Kraus and Jordan, 1965). Odontometric characteristics of each molar crown are thought to represent a cumulative effect of individual cusp dimensions (Kanazawa et al., 1985), so analysis based on measurement of cusp dimensions promises to be more meaningful biologically than conventional measurements of whole crowns.

Teeth that develop later in ontogeny are expected to display greater sexual dimorphism due to the increasing differences in sex hormone production between males and females (Gingerich, 1974). In mandibular molars, sexual dimorphism values were shown to be greater in talonid dimensions than in the trigonid, suggesting that sexual dimorphism is larger in the later developed crown units (Yamada, 1981). The present study focuses on the sexual dimorphism of cusp diameters in the first maxillary molar and tests the hypothesis that the later developed distal cusps should display greater dimorphism than earlier developing mesial cusps.

Correspondence to: Gaurav Agnihotri, Lecturer, Government Medical College, Amritsar, Punjab, India. E-mail: anatomygaurav@rediffmail.com. 


\section{MATERIALS AND METHODS}

\section{Selection Criteria}

One hundred subjects (50 males, 50 females) in the age interval of 17-21 years were selected for the study because attrition is considered to be minimal in this age group. The study was conducted on the students enrolled in the Government Medical College, Patiala, India, and the Government Medical College, Amritsar, India. Consent of the subjects was obtained, and the study casts were made with the help of resident doctors, senior residents, and senior technicians at the local Government Dental College.

Only those Jat Sikh students were selected whose upper and lower arches fulfilled the following inclusion criteria.

- Healthy state of gingiva and peridontium,

- caries free teeth,

- normal overjet and overbite,

- absence of spacing in the anterior teeth,

- normal molar and canine relationship, and

- clearly distinguishable central pit of first maxillary molar.

\section{Odontometry}

Measurements were taken with a vernier caliper with a precision of $0.02 \mathrm{~mm}$. The following parameters were measured and computed: (A) the mesiodistal and buccolingual crown diameters and cusp diameters (Fig. 1); (B) the mesiodistal (Fig. 2) and buccolingual (Fig. 3) crown diameters and cusp diameters (Fig. 4). Each cusp diameter is defined as the diagonal distance from

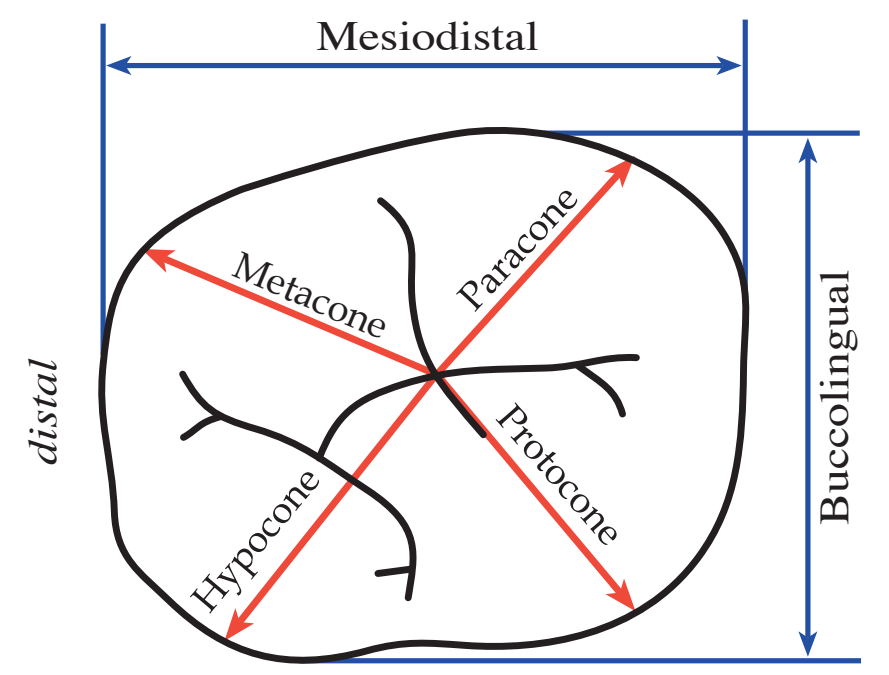

\section{lingual}

Fig. 1. Illustration of the measurement of crown dimensions.

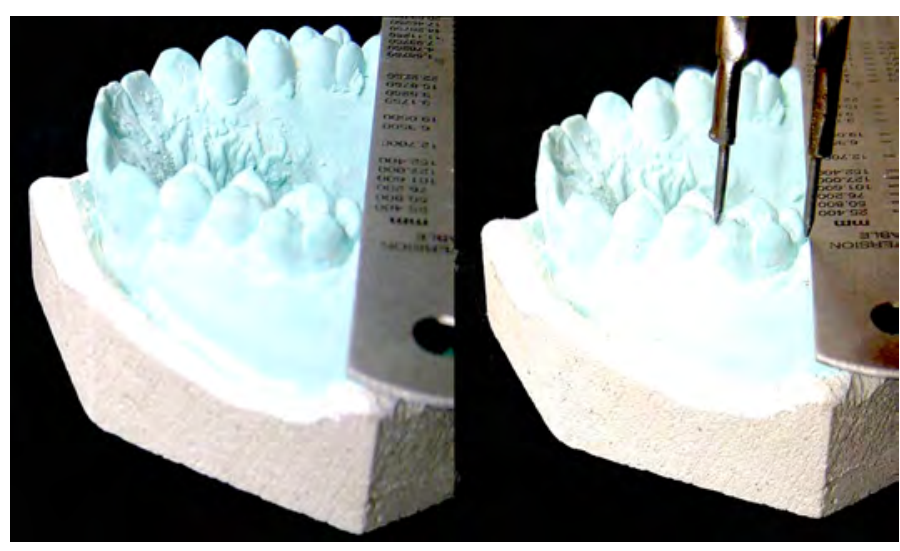

Fig. 2. Illustration showing the measurement of maximum mesiodistal crown dimension.

the central pit to the most prominent convexity on the crown outline corresponding to the relevant cusp, taken perpendicular to the axis of the tooth (Kondo, 1985).

Three additional variables were calculated for each of these dimensions:

The crown area provides a measure of overall crown size:

$$
\text { Crown area }=\mathrm{MD} \times \mathrm{BL}
$$

where $\mathrm{MD}$ is the mesiodistal width and $\mathrm{BL}$ is the buccolingual length.

The cusp index quantifies cusp size relative to overall crown size:

$$
\text { Cusp index }=\frac{\text { Cusp diameter }}{\sqrt{\mathrm{MD} \times \mathrm{BL}}} 100
$$

And, sexual dimorphism:

$$
\text { Sexual dimorphism }=\frac{M-F}{M} 100
$$

where $\mathrm{M}$ and $\mathrm{F}$ are the mean values in males and females. This formula is applicable for computing sexual dimorphism in mesiodistal width, buccolingual length, and crown area.

\section{Statistical Analysis}

Descriptive statistics, including distribution parameters, were calculated using Origin 6.1 software (Origin Lab Corporation, USA, version 6.1052 for Windows). Unpaired t-tests were used to compare the dimensions measured for males and females, and a table of the $t$ distribution was consulted. Attainment of statistical significance was set at alpha $=0.01$.

\section{RESULTS}

The results have been depicted in Tables 1, 2, 3 and 4. The study quantifies the morphometric criterion for the maxillary first molars in Jat Sikhs. In general the morphometric parameters were found to be quantitatively higher for the left side.

The study establishes the existence of statistically 
TABLE 1. Descriptive statistics and tests for sexual dimorphism between males and females

\begin{tabular}{|c|c|c|c|c|c|c|}
\hline Parameter & Side & Sex & Mean & $\mathrm{sd}$ & t-test & P-value ${ }^{1}$ \\
\hline \multirow[t]{4}{*}{ Mesiodistal Width } & \multirow[t]{2}{*}{ Right } & Males & 11.33 & 0.078 & \multirow[t]{2}{*}{-19.88} & \multirow[t]{2}{*}{$<0.01$} \\
\hline & & Females & 10.88 & 0.142 & & \\
\hline & \multirow[t]{2}{*}{ Left } & Males & 11.39 & 0.195 & \multirow[t]{2}{*}{-13.53} & \multirow[t]{2}{*}{$<0.01$} \\
\hline & & Females & 10.87 & 0.187 & & \\
\hline \multirow[t]{4}{*}{ Buccolingual Length } & \multirow[t]{2}{*}{ Right } & Males & 12.53 & 0.078 & \multirow[t]{2}{*}{-19.51} & \multirow[t]{2}{*}{$<0.01$} \\
\hline & & Females & 11.98 & 0.192 & & \\
\hline & \multirow[t]{2}{*}{ Left } & Males & 12.60 & 0.192 & \multirow[t]{2}{*}{-18.26} & \multirow[t]{2}{*}{$<0.01$} \\
\hline & & Females & 11.98 & 0.142 & & \\
\hline \multirow[t]{4}{*}{ Crown Area } & \multirow[t]{2}{*}{ Right } & Males & 142.07 & 1.859 & \multirow[t]{2}{*}{-24.83} & \multirow[t]{2}{*}{$<0.01$} \\
\hline & & Females & 130.29 & 2.789 & & \\
\hline & \multirow[t]{2}{*}{ Left } & Males & 143.54 & 4.617 & \multirow[t]{2}{*}{-17.33} & \multirow[t]{2}{*}{$<0.01$} \\
\hline & & Females & 130.25 & 2.849 & & \\
\hline \multirow[t]{4}{*}{ Paracone Diameter } & \multirow[t]{2}{*}{ Right } & Males & 5.82 & 0.118 & \multirow[t]{2}{*}{-8.73} & $<0.01$ \\
\hline & & Females & 5.63 & 0.124 & & \\
\hline & Left & Males & 5.84 & 0.138 & -11.19 & $<0.01$ \\
\hline & & Females & 5.64 & 0.089 & & \\
\hline Protocone Diameter & Right & Males & 5.88 & 0.119 & -13.39 & $<0.01$ \\
\hline & & Females & 5.59 & 0.108 & & \\
\hline & Left & Males & 5.90 & 0.089 & -16.83 & $<0.01$ \\
\hline & & Females & 5.60 & 0.078 & & \\
\hline Metacone Diameter & Right & Males & 5.68 & 0.117 & -13.48 & $<0.01$ \\
\hline & & Females & 5.39 & 0.088 & & \\
\hline & Left & Males & 5.70 & 0.102 & -16.39 & $<0.01$ \\
\hline & & Females & 5.40 & 0.079 & & \\
\hline Hypocone Diameter & Right & Males & 6.98 & 0.122 & -21.19 & $<0.01$ \\
\hline & & Females & 6.51 & 0.104 & & \\
\hline & Left & Males & 7.00 & 0.102 & -25.80 & $<0.01$ \\
\hline & & Females & 6.52 & 0.092 & & \\
\hline Paracone Index & Right & Males & 48.82 & 1.114 & 2.46 & n.s. \\
\hline & & Females & 49.31 & 0.902 & & \\
\hline & Left & Males & 48.74 & 0.982 & 3.72 & n.s. \\
\hline & & Females & 49.43 & 0.862 & & \\
\hline Protocone Index & Right & Males & 49.32 & 1.102 & -1.77 & n.s. \\
\hline & & Females & 48.96 & 0.901 & & \\
\hline & Left & Males & 49.24 & 0.983 & -0.91 & n.s. \\
\hline & & Females & 49.08 & 0.853 & & \\
\hline Metacone Index & Right & Males & 47.65 & 1.089 & -2.17 & n.s. \\
\hline & & Females & 47.23 & 0.882 & & \\
\hline & Left & Males & 47.59 & 0.982 & -1.46 & n.s. \\
\hline & & Females & 47.32 & 0.845 & & \\
\hline Hypocone Index & Right & Males & 58.45 & 1.104 & -7.12 & $<0.01$ \\
\hline & & Females & 57.14 & 0.908 & & \\
\hline & Left & Males & 58.55 & 1.137 & -6.46 & $<0.01$ \\
\hline
\end{tabular}

${ }^{1}$ Statistical significance was set at $\mathrm{P}<0.01$; ns $=$ not significant $(\mathrm{P}>0.01)$.

significant sexual dimorphism $(\mathrm{P}<0.01)$ for the maxillary compared, they are found to be statistically insignificant. first molars in Jat Sikhs. From Table 1, it is evident that From these findings, it can be inferred that there exists the parameters as measured for males and females when a definite statistically significant sexual dimorphism for compared are found to be statistically significant. Further the maxillary first molar in Indian Jat Sikhs $(\mathrm{P}<0.01)$. in males or females individually, i.e. within the same sex The percentage sexual dimorphism calculated came out (Tables 2 and 3) when these parameters as measured, are to be higher for the buccolingual dimension $(4.6 \%$ for 


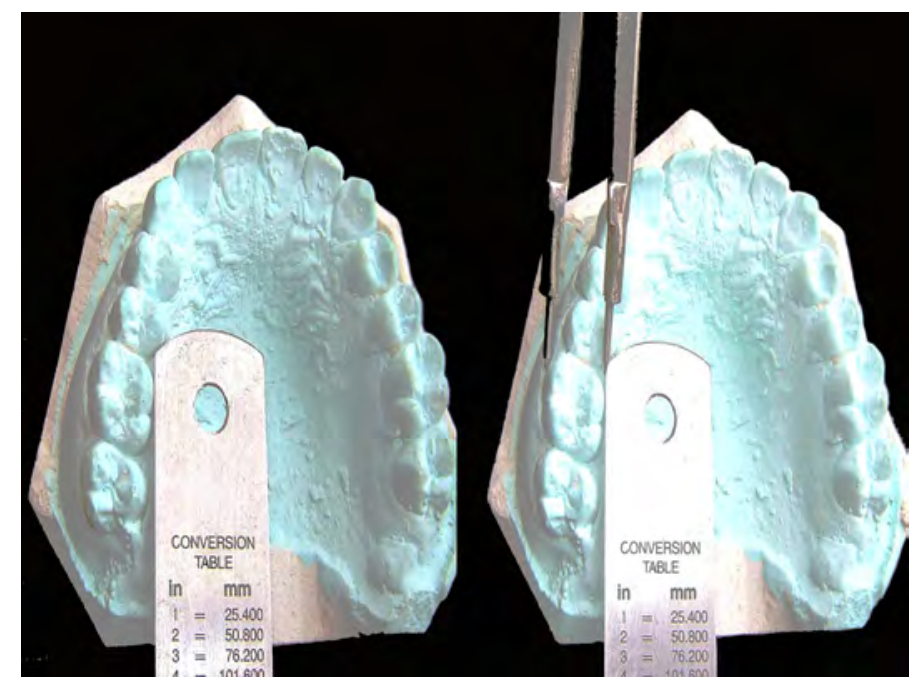

Fig. 3. Illustration showing the measurement of maximum buccolingual crown dimension.

the right side and $5.2 \%$ for the left side) as compared to the mesiodistal dimension. Among the various crown dimensions, crown area displays the maximum dimorphism ( $9.0 \%$ for right side and $10.2 \%$ for left side).

The maximum cusp size in decreasing order came out to be hypocone $>$ protocone $>$ paracone $>$ metacone for these Indian Jat Sikhs. The sex dimorphism in the cusp dimensions corresponds to the order of cusp formation, namely, hypocone $>$ metacone $>$ protocone $>$ paracone. The percentage sexual dimorphism for the hypocone (right $7.2 \%$; left $7.4 \%$ ) is quite high in present study as compared to the other cusps. The cusp index exhibited the sequence: hypocone index $>$ protocone index $>$ paracone index $>$ metacone index. The cusp indices (except for the hypocone index) did not exhibit statistically significant sexual dimorphism.

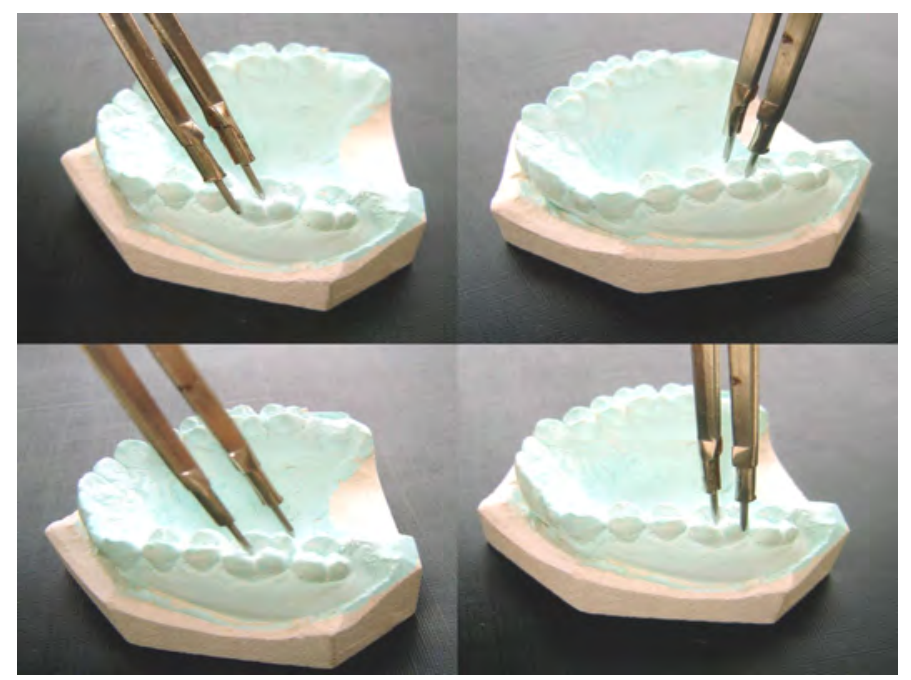

Fig. 4. Depiction of the method of measuring cusp diameters. Clockwise from the upper left are the paracone, protocone, metacone, and hypocone.

\section{DISCUSSION}

Dental morphological characteristics are useful for providing information for phylogenic and genetic studies and understanding variation within and among species. The crown characteristics are known to differ among racial groups; for example, Australian aborigines have larger teeth, Indians have smaller teeth, while whites have teeth intermediate in size (Tedeschi, 1977).

The Jat Sikhs are an endogamous group at caste level. They have distinct customs, traditions and food habits. As such the present study defines the criteria of the first molar tooth size for the Jat Sikhs. In general the morphometric parameters were found to be quantitatively higher for the left side. This observation holds true also for all the maxillary anterior teeth in North Indians (Agnihotri and Jain, 2008) but not in South Indians (Nair et al., 1999). The crown dimensions for the first molar are comparable to those of the Jats (Kaul and Prakash, 1984) in Haryana. The Jats of Haryana constitute an agriculture-based community in North India.

It is a combination of environmental factors and inheritance that controls the mesiodistal and buccolingual dimensions. The dimensions obtained for the male teeth are definitely on the higher side as compared to those for females. This can be explained on the basis of the shape of the first molar tooth, which is controlled by the genetic constitution of the individual. Thus, the male teeth are usually larger in size as compared to the female teeth. It is the $\mathrm{Y}$ chromosome that seems to contribute most in the size of teeth by controlling the thickness of dentine, whereas the $X$ chromosome seems to be responsible for modulating thickness of the enamel. The sexual dimorphism in tooth morphology is attributable to the presence of relatively more dentine in the crowns of male teeth (Iscan and Kedici, 2003).

The present study indicates that there exists a definite statistically significant sexual dimorphism for the maxillary first molar in Indian Jat Sikhs $(\mathrm{P}<0.01)$. This is in concordance with the work done on Taiwan Chinese (Kondo, 1998) and on Jordanian subjects (Hattab et al., 1996). While dental difference between the sexes in several human groups has been found highly dimorphic, it was not found so in Turks (Iscan and Kedici, 2003), where the lack of dimorphism comes from male subjects. This validates the perception that sexual dimorphism is population specific.

The percentage sexual dimorphism calculated came out to be higher for the buccolingual dimension $(4.6 \%$ for the right side and $5.18 \%$ for the left side) as compared to the mesiodistal dimension. This is consonant with the findings for American white (Garn et al., 1966) and South Indian (Nair et al., 1999) subjects. Since size dimorphism was consistently greater for the buccolingual tooth diameter, its more extensive use is indicated in like-sex and unlike-sex sibling and parent-child comparisons for tooth size. Among the various crown dimensions, crown 
TABLE 2. Descriptive statistics and tests for left-right side differences in males

\begin{tabular}{lcrrrrrrr}
\hline \multicolumn{1}{c}{ Parameter } & Side & Mean & sd & Side & Mean & sd & t-test & P-value \\
\hline Mesiodistal Width & Left & 11.39 & 0.195 & Right & 11.33 & 0.078 & 1.96 & $>0.01$ \\
Buccolingual Length & Left & 12.60 & 0.192 & Right & 12.53 & 0.078 & 2.13 & $>0.01$ \\
Crown Area & Left & 143.54 & 4.617 & Right & 142.07 & 1.859 & 2.01 & $>0.01$ \\
Paracone Diameter & Left & 5.84 & 0.138 & Right & 5.82 & 0.118 & 0.91 & $>0.01$ \\
Protocone Diameter & Left & 5.90 & 0.089 & Right & 5.88 & 0.119 & 0.92 & $>0.01$ \\
Metacone Diameter & Left & 5.70 & 0.102 & Right & 5.68 & 0.117 & -0.90 & $>0.01$ \\
Hypocone Diameter & Left & 7.00 & 0.102 & Right & 6.98 & 0.122 & 0.96 & $>0.01$ \\
Paracone Index & Left & 48.74 & 0.982 & Right & 48.82 & 1.114 & -0.35 & $>0.01$ \\
Protocone Index & Left & 49.24 & 0.983 & Right & 49.32 & 1.102 & -0.36 & $>0.01$ \\
Metacone Index & Left & 47.59 & 0.982 & Right & 47.65 & 1.089 & -0.32 & $>0.01$ \\
Hypocone Index & Left & 58.55 & 1.137 & Right & 58.45 & 1.104 & -0.48 & $>0.01$ \\
\hline
\end{tabular}

area displayed the maximum dimorphism $(9.0 \%$ for right side; $10.2 \%$ for left side).

The present pioneer study on the maxillary molar tooth in Indian Jat Sikhs provides data useful for anthropological, genetic, odontologic, and forensic investigations. This is particularly so since tooth morphology is known to be influenced by cultural, environmental, and racial factors (Agnihotri and Gulati, 2008).

The maximum cusp size in decreasing order came out to be hypocone $>$ protocone $>$ paracone $>$ metacone. This order has been found to differ among populations. For the Japanese, Kondo et al. (2005) found the sequence to be: protocone $>$ hypocone $>$ paracone. For American whites, Biggerstaff (1976) reported the order to be protocone> metacone $>$ paracone $>$ hypocone. The sexual dimorphism in the cusp dimensions corresponds to the order of cusp formation, namely hypocone $>$ metacone $>$ protocone $>$ paracone. Thus, the ontogenetic hypothesis, that later forming structures show greater sexual dimorphism than earlier forming structures, can apparently be extended to dental crown components.

The hypocone is considered to be the key innovation in mammalian evolution (Hunter and Jernvall, 1995).
Mammals that developed the hypocone became preadapted for masticating fibrous plants and subsequently demonstrated a markedly increased species diversity. The percentage sexual dimorphism for the hypocone (right $7.2 \%$; left $7.4 \%$ ) is high in present study as compared to the other cusps. This value is in fact comparable to the values for canine in North Indian population (right 7.3\%; left $8.1 \%$ ). The canine is known to exhibit the largest sexual dimorphism in the human dentition.

The cusp index exhibited the sequence: hypocone index $>$ protocone index $>$ paracone index $>$ metacone index. However in the present study the cusp indices except the hypocone index did not demonstrate a statistically significant sexual dimorphism. Though the cusp index sequence follows the same pattern in the Japanese (Kondo et al., 2005), the hypocone index in them is statistically significant. This can be attributed to differences in ethnicity. The hypocone index and hypocone diameter are the most dimorphic parameters for the Jat Sikh population.

\section{CONCLUSION}

The study quantifies the morphometric criterion and

TABLE 3. Descriptive statistics and tests for left-right side differences in females

\begin{tabular}{lcrllrrrr}
\hline \multicolumn{1}{c}{ Parameter } & Side & Mean & sd & Side & Mean & sd & t-test & P-value \\
\hline Mesiodistal Width & Left & 10.87 & 0.187 & Right & 10.88 & 0.142 & -0.13 & $>0.01$ \\
Buccolingual Length & Left & 11.98 & 0.142 & Right & 11.97 & 0.192 & 0.13 & $>0.01$ \\
Crown Area & Left & 130.25 & 2.849 & Right & 130.29 & 2.789 & -0.08 & $>0.01$ \\
Paracone Diameter & Left & 5.64 & 0.089 & Right & 5.63 & 0.124 & 0.69 & $>0.01$ \\
Protocone Diameter & Left & 5.60 & 0.078 & Right & 5.59 & 0.108 & 0.68 & $>0.01$ \\
Metacone Diameter & Left & 5.40 & 0.079 & Right & 5.39 & 0.088 & 0.57 & $>0.01$ \\
Hypocone Diameter & Left & 6.52 & 0.092 & Right & 6.51 & 0.104 & 0.59 & $>0.01$ \\
Paracone Index & Left & 49.43 & 0.862 & Right & 49.31 & 0.902 & 0.64 & $>0.01$ \\
Protocone Index & Left & 49.08 & 0.853 & Right & 48.96 & 0.901 & 0.65 & $>0.01$ \\
Metacone Index & Left & 47.32 & 0.845 & Right & 47.23 & 0.882 & 0.55 & $>0.01$ \\
Hypocone Index & Left & 57.03 & 0.989 & Right & 57.14 & 0.908 & 0.55 & $>0.01$ \\
\hline
\end{tabular}


TABLE 4. Sexual dimorphism for the crown and cusp dimensions

\begin{tabular}{lcr}
\hline \multicolumn{1}{c}{ Parameter } & Right side & Left side \\
\hline Mesiodistal width & $4.14 \%$ & $4.78 \%$ \\
Buccolingual length & $4.68 \%$ & $5.18 \%$ \\
Crown area & $9.04 \%$ & $10.20 \%$ \\
Paracone & $3.37 \%$ & $3.55 \%$ \\
Protocone & $5.19 \%$ & $5.36 \%$ \\
Metacone & $5.38 \%$ & $5.56 \%$ \\
Hypocone & $7.22 \%$ & $7.36 \%$ \\
\hline
\end{tabular}

establishes the existence of a statistically significant sexual dimorphism $(\mathrm{P}<0.01)$ for the maxillary first molars in Jat Sikhs. This study suggests that the hypocone index and hypocone diameter are the most dimorphic parameters for the Jat Sikh population.

\section{ACKNOWLEDGEMENTS}

The authors would like to thank Dr. Satish Agnihotri, Colonel (Retd) and Dr. Vikram Agnihotri (Capt) for their invaluable suggestions and encouragement. We also appreciate our statistician Mrs. Shaweta Agnihotri, Lecturer, BBK DAV College, Amritsar for her efforts and hard work. We are indebted to the resident doctors, senior residents, and senior technicians working in the local Government Dental College for their wholehearted support for the timely completion of the study.

\section{LITERATURE CITED}

Agnihotri G, Gulati MS. 2008. Maxillary molar and premolar indices in North Indians: a dimorphic study. The Internet Journal of Biological Anthropology [vol 2, no 1] Available from: http://www.ispub.com/ostia/ index.php.

Agnihotri G, Jain RL. 2008. Maxillary anterior teeth morphometry in North Indians: a dimorphic study. Nepal Dent J 9:23-28.

Biggerstaff RH. 1976. Cusp size, sexual dimorphism, and the heritability of maxillary molar cusp size in twins. J Dent Res 55:189-195.

Black GV. 1902. Description of human teeth, 4th ed. Philadelphia: S.S. White Manufacturing Company.

Camps. 1976. Identification by skeletal structures. In: Gradwohls legal medicine, 3rd ed. London: John Wright and Sons.

Dayal PK, SrinivasanSV, Paravatty RP.1998. Determination of sex using tooth. In: Masthan Kmk, editor. Textbook of forensic odontology. Hyderabad: Paras Medical Publisher.

Dhillon BS. 1994. History and study of the Jats. India: Beta Publishers.

Kraus BS, Jordan RE. 1965. The human dentition before birth. Philadelphia: Lea and Febiger.

Garn SM, Lewis AB, Kerewsky RS. 1966. Sexual dimorphism in the buccolingual tooth diameter. J Dent Res 45:1819.

Gingerich PD. 1974. Size variability of the teeth in living mammals and the diagnosis of closely related sympatric fossil species. J Paleontol 48:895-903.

Hattab FN, al-Khateeb S, Sultan I. 1996. Mesiodistal crown diameters of permanent teeth in Jordanians. Arch Oral Biol 41:641-645.

Hunter JP, Jernvall J. 1995. The hypocone as a key innovation in mammalian evolution. Proc Natl Acad Sci 92:10718-10722.

Iscan MY, Kedici PS. 2003 Sexual variation in buccolingual dimensions in Turkish dentition. Forensic Sci Int 2:160-164.

Kanazawa E, Sekikawa M, Akai J, Ozaki T. 1985. Allometric variation on cuspal areas of the lower first molar in three racial populations. J Anthropol Soc Nippon 9:425-438.

Kaul V, Prakash S. 1984. Crown dimensions of deciduous and permanent teeth of Jats from Haryana (India). Ann Hum Biol 11:351-354.

Kondo S, Yamada H. 1985. Cusp size variability of the maxillary molariform teeth. Anthropol Sci 111:255-263.

Kondo S.1998. Sexual dimorphism in the tooth crown dimensions of the second deciduous and first permanent molars of Taiwan Chinese. Okajimas Folia Anat Jpn 75:239-246.

Kondo S, Townsend GC, Yamada H. 2005. Sexual dimorphism of cusp dimensions in human maxillary molars. Am J Phys Anthropol 128:870-877.

Nair P, Rao BB, Annigeri RG. 1999. A study of tooth size, symmetry and sexual dimorphism. J Forensic Med Toxicol 16:10-13.

Osborn HF. 1907. Trituberculy in relation to the human molar teeth and primates. In: Gregory WK, editor. Evolution of mammalian molar teeth to and from the triangular type. New York: Macmillan, p 48-65.

Patterson B. 1956. Early Cretaceous mammals and the evolution of mammalian molar teeth. Fieldiana Geol 1956;23:1-105.

Sidhu IS, Kaur K, Sarhadi VK, Joshi DS, Mukhopadhaya R, Mahajan SK, Bhanwer AJS. 2003. Study of genetic polymorphism at D21S11 and D21S215 loci in the Jat Sikh population of Punjab. Int J Hum Genet 3:45-50.

Tedeschi CG. 1977. Examination of human remains. In: Tedeschi CG, Eckert WG, Tedeschi LG, editors. Forensic medicine. Philadelphia: WB Saunders Company.

Yamada H. 1981. Sexual dimorphism of molar crown size in a Japanese population. Jpn J Oral Biol 34:531-540. 